\title{
A COMPACT ANTENNA DESIGN FOR FIFTH GENERATION WIRELESS COMMUNICATION SYSTEM
}

\author{
${ }^{1}$ N. N. Daud, ${ }^{1}$ M. N. Osman, ${ }^{2}$ M.R.Kamarudin, ${ }^{3}$ A.R.Kram, ${ }^{4}$ M.M.Azizan \\ ${ }^{1}$ Bioelectromagnetic Research Group (BioEM), School of Computer and Communication Engineering, Universiti Malaysia Perlis, \\ 02600 Arau, Perlis, Malaysia. \\ ${ }^{2}$ Centre for Electronic Warfare, Information and Cyber (EWIC) Cranfield Defence and Security, Cranfield University \\ ${ }^{3}$ Faculty of Engineering, Department of Electrical Electronic, University Malaysia Sarawak \\ ${ }^{4}$ School of Electrical System Engineering, Universiti Malaysia Perlis, 02600 Arau, Perlis, Malaysia
}

\begin{abstract}
This paper proposes a compact antenna design for wireless communication system that can operate at dual band frequencies which are $24.25 \mathrm{GHz}$ and $38 \mathrm{GHz}$. The antenna with an overall size of 6.3 $\mathrm{mm}$ X $6.0 \mathrm{~mm}$ is printed on RogersRT5880 type of substrate with a thickness of $0.787 \mathrm{~mm}$. The simulated reflection coefficient result is $<-10 \mathrm{~dB}$ for both frequencies which makes it suitable for $5 \mathrm{G}$ applications. The proposed antenna has a stable gain value of $7.23 \mathrm{dBi}$ at $24.25 \mathrm{GHz}$ and $3.69 \mathrm{dBi}$ at $38 \mathrm{GHz}$. All the simulation result was performed by using CST Microwave Studio Software. The result shows the feasibility of this antenna to be applied for future $5 \mathrm{G}$ application.
\end{abstract}

\section{Introduction}

Industry of mobile and wireless communication has widely grown over the last decade starting from analog to digital system like $2 \mathrm{G}$ (GSM) then towards high data rate wireless communication which is WCDMA or known as 3G. Evolution of the communication does not stop here, but it continues to grow in the presence of $3.5 \mathrm{G}$ (HSPA) and $4 \mathrm{G}$ or also known as LTE and LTE-A. Today, 5G pilot studies are going on and expected to be released in 2020 and beyond [1]. 5G or also familiarly known as millimeter wave is needed in order to overcome existing problems such as slow data rate and spectrum scarcity. Fifth generation also provides a better coverage compared to previous generation [2]. In order to fulfil all the requirements of the modern technologies, a new design of patch antenna is proposed in this paper. One of the major challenge to design a high frequency antenna is the size of the antenna become smaller thus the fabrication process become more challenging.

Nowadays, microstrip antenna plays a main role in the wireless communications industry. Microstrip antenna has several advantages such as low cost, light weight, ease of integration into arrays, and also produces the best result for mobile radio and wireless communication due to its planar configuration [3]. Moreover, microstrip antenna is perfectly suited for many applications that requires a low profile antenna because it can adapt to a given shape easily. The most important advantage of microstrip antenna is this type of antenna is capable of operating at dual and triple frequency operations [4]. Furthermore, microstrip antenna also easy to feed by using coaxial cable and mictrostrip lines.

In theory, an antenna that has dual band frequencies should operate with similar features at two separate frequencies in term of radiation and also its impedance matching [5]. Moreover, one of the advantages of implementing a dual frequency patch antenna is we can avoid the use of two different antennas when the system requires operation of two significantly dual different frequencies.

This proposed antenna could provide the communications for fifth generation wireless communication system applications which has a high data rate and better coverage compared to previous generations.

\section{Antenna Design}

The main objective of this research is to design a compact antenna that capable of operating at dual band frequencies of high frequency millimeter wave. Some basic calculation of the antenna will be considered in order to begin this research. The antenna was designed at RTRogers5880 as a substrate with a thickness of $0.787 \mathrm{~mm}$, with relative permittivity $\mathrm{\varepsilon r}=2.2$ and loss tangent of 0.0009 . In fact, this type of substrate shows a better performance compared with LTCC technology [6]. The patch of the antenna uses copper as a material with a dimension of $4.6 \times 3.6 \mathrm{~mm}$ with the thickness of $0.035 \mathrm{~mm}$. Moreover, copper is a material that high conductivity compared to others. 
Figure 1 shows a front view and side view of a single antenna design with all the dimensions involved while the summary of antenna specification for fifth generation wireless communication is summarized in Table 1.

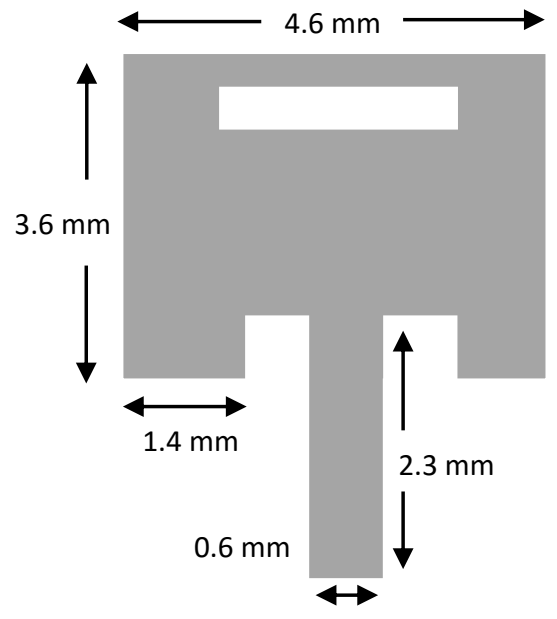

(a)

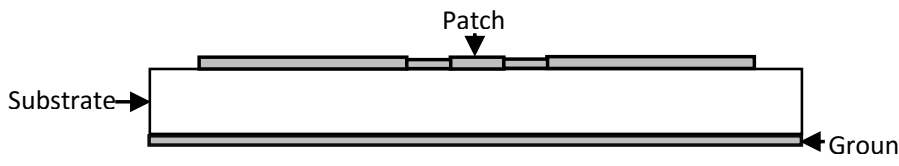

(b)

Fig 1. Front view of single antenna design (a) side view of single antenna (b).

Table 1. Antenna Specification

\begin{tabular}{cc}
\hline Shape & Rectangular \\
\hline Frequency & $24.25 \mathrm{GHz}, 38 \mathrm{GHz}$ \\
Dielectric constant, $\boldsymbol{\varepsilon}$ & 2.2 \\
Substrate & RogersRT5880 \\
Thickness of substrate, $\mathbf{h}$ & $0.787 \mathrm{~mm}$ \\
\hline
\end{tabular}

\section{Result and Discussion}

Design methodology for a rectangular patch microstrip antenna will be discussed in this section. Computer simulation technology (CST) microwave studio is the tools that have been used to analyze and optimize the performance of the antenna. Figure 2 depicts a parameter optimization of two important parameters which are XY and YZ.

Figure 3 indicates the simulated result of the reflection coefficient for the proposed millimeter wave antenna in five different values of $\mathrm{XY}$ which is $1.0 \mathrm{~mm}$, $1.2 \mathrm{~mm}, 1.4 \mathrm{~mm}, 1.6 \mathrm{~mm}$ and lastly $1.8 \mathrm{~mm}$. It is obvious that this compact antenna can cover both 24.25
$\mathrm{GHz}$ and $38 \mathrm{GHz}$ frequencies with a result of $\mathrm{S}_{11}$ is $25.204 \mathrm{~dB}$ and $-13.625 \mathrm{~dB}$ at the second band when the value of $X Y=1.8 \mathrm{~mm}$.

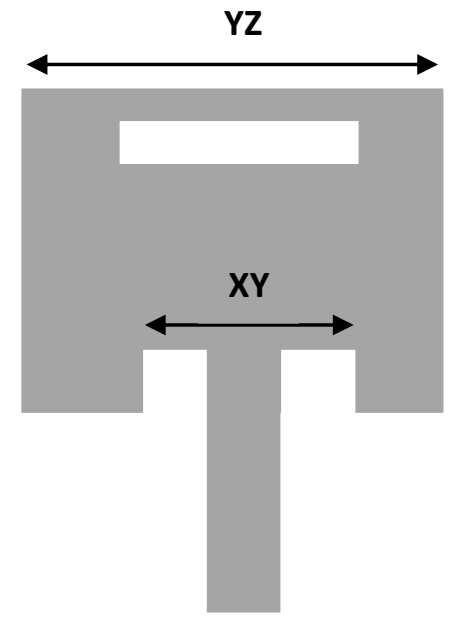

Fig 2. Parameter optimization

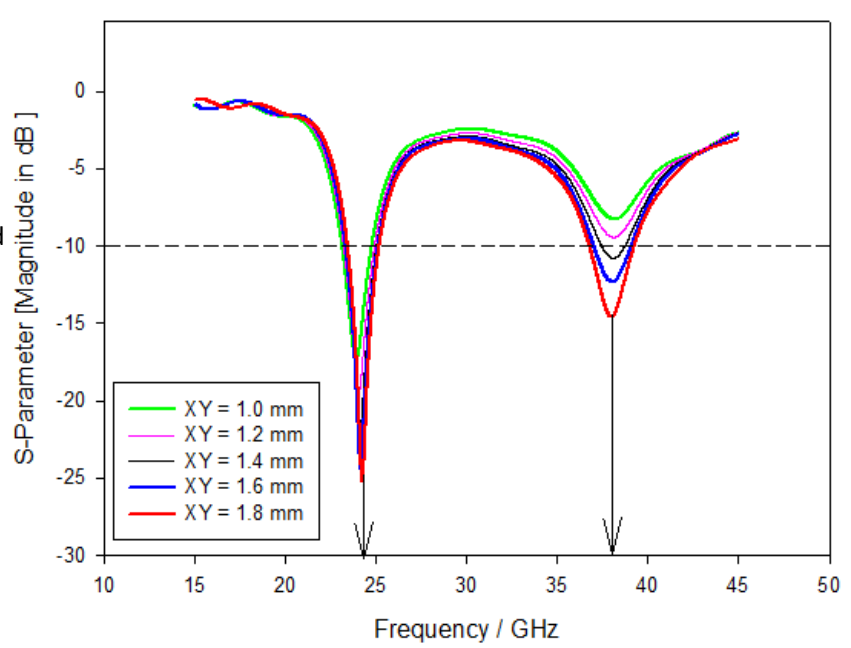

Fig 3. Reflection Coefficient for various XY

Principally, a good performance of antenna is when the frequency drop is less than $-10 \mathrm{~dB}$ or $<-10 \mathrm{~dB}$. Reflection coefficient or normally known as $\mathrm{S}_{11}$ indicates a parameter that describes how much power is propagated from the antenna [7].

Moreover, in order to improve the frequency drop and the achieved gain of the desired antenna, the tuning of length of $\mathrm{YZ}$ is also required. There are also five different value needs to be adjusted which are when YZ is equal to $2.0 \mathrm{~mm}, 2.2 \mathrm{~mm}, 2.4 \mathrm{~mm}, 2.6 \mathrm{~mm}$ and 2.8 $\mathrm{mm}$. The simulated of the reflection coefficient of the tuning process can be express in the next Figure 4. 


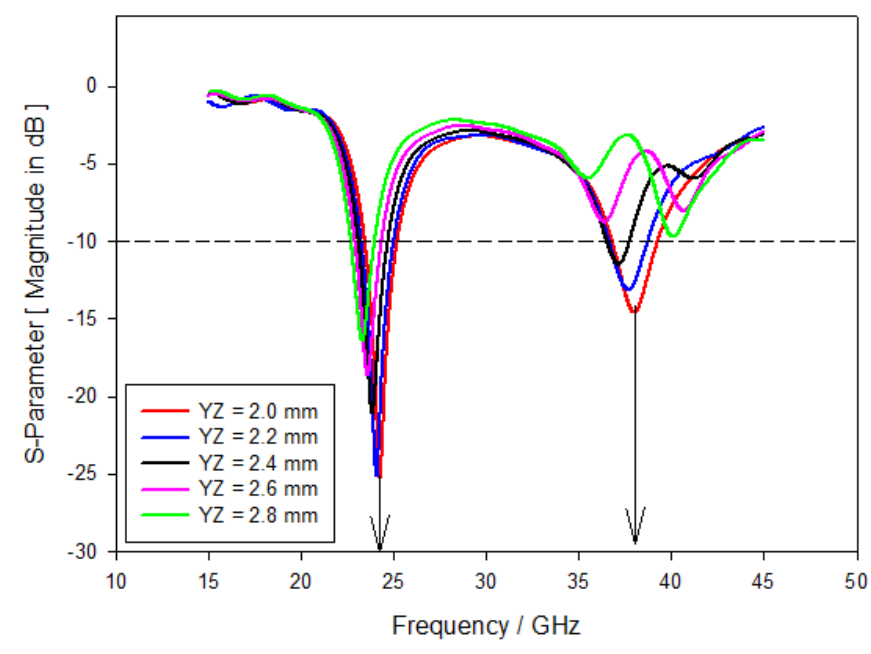

Fig. 4 Adjustable value of length YZ

Sequentially, Figure 5 illustrates the maximum gain achieved for (a) $24.25 \mathrm{GHz}$ and (b) $38 \mathrm{GHz}$ respectively. A stable gain of $7.23 \mathrm{dBi}$ at $24.25 \mathrm{GHz}$ and $3.69 \mathrm{dBi}$ at $38 \mathrm{GHz}$ was achieved. In fact, gain is a measurement of the ability of the antenna to direct the input power into radiation in a particular direction and is measured at the peak intensity.
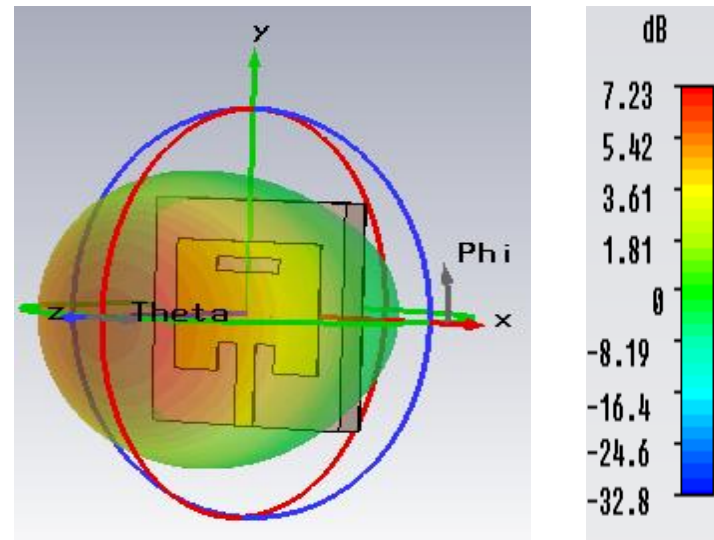

(a)

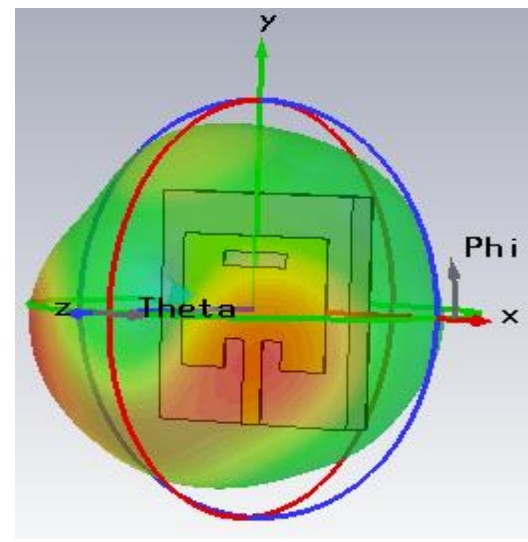

$d B$

3.69

2.77

1.84

0.922

$-9.68$

$-18.2$

$-27.2$

$-36.3$

(b)

Fig 5. Maximum gain achieved for (a) $24.25 \mathrm{GHz}$ and (b) 38 $\mathrm{GHz}$
Next, Fig. 6 depicts the simulated radiation pattern the proposed antenna at dual band frequencies of $24.25 \mathrm{GHz}$ and $38 \mathrm{GHz}$ for future millimeter wave communication system. The total efficiency of this antenna is $75 \%$ which is good in order to operate in $5 \mathrm{G}$ applications.

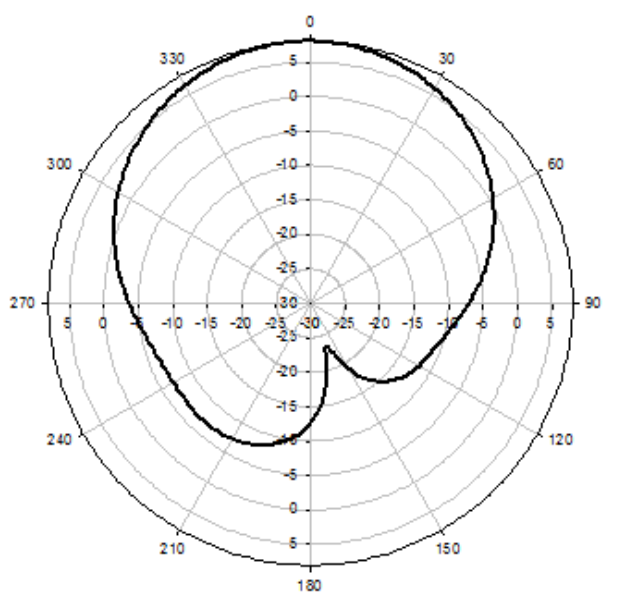

(a)

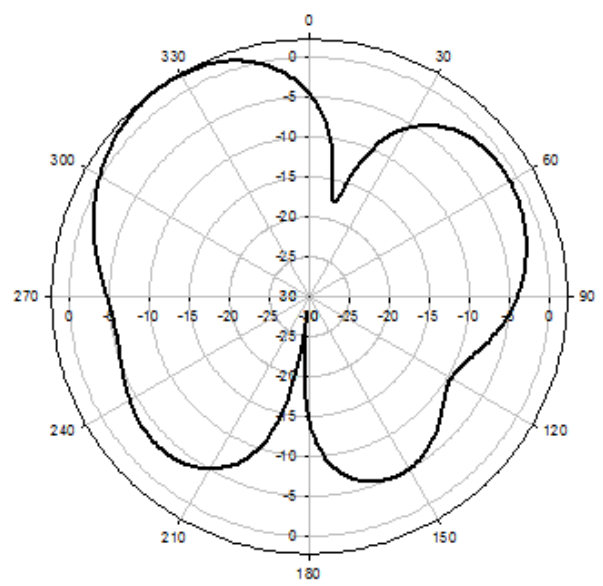

(b)

Fig. 6. Simulated Radiation pattern for (a) $24.25 \mathrm{GHz}$ and (b) $38 \mathrm{GHz}$

\section{Conclusion}

A compact antenna design for fifth generation wireless communication system is proposed and discussed in this work. The proposed antenna operates successfully at two different frequencies which are 24.25 $\mathrm{GHz}$ and $38 \mathrm{GHz}$. The simulated antenna shows better performance in term of frequency drop, gain achieved and radiation pattern as well. This antenna has physical size with a compact size, simple structure and high efficiency to cover all the requirement of 5G. All these properties make it a good candidate for future millimeter wave application. 


\section{Acknowledgement}

The authors would like to deeply thank University Malaysia Perlis (UniMAP) for financial support which to enable this research to be carried out. Once again, a big thanks to all members of School of Computer and Communication Engineering especially the members of ENAC Lab of UniMAP.

\section{References}

1. Gampala, G., \& Reddy, C. J. (2016, March). Design of millimeter wave antenna arrays for $5 \mathrm{G}$ cellular applications using FEKO. In 2016 IEEE/ACES International Conference on Wireless Information Technology and Systems (ICWITS) and Applied Computational Electromagnetics (ACES) (pp. 1-2). IEEE.

2. Kumar, A., \& Kapoor, P. (2016, May). Design and performance evaluation of a dual-band antenna for the 5G mobile communication. In Recent Trends in Electronics, Information \& Communication Technology (RTEICT), IEEE International Conference on (pp. 2034-2036). IEEE.

3. Yaseen, M. T. (2013). Design of Dual-Band Antenna for Wireless Communication Applications (Doctoral dissertation, University of Technology).

4. https://www.slideshare.net/totitarek/microstripantenna-15491076

5. Maci, S., \& Gentili, G. B. (1997). Dual-frequency patch antennas. IEEE Antennas and Propagation Magazine, 39(6), 13-20.

6. Outerelo, D. A., Alejos, A. V., Sanchez, M. G., \& Isasa, M. V. (2015, July). Microstrip Antenna for $5 \mathrm{G}$ Broadband Communications: Overview of Design Issues. In 2015 IEEE International Symposium on Antennas and Propagation \& USNC/URSI National Radio Science Meeting (pp. 2443-2444). IEEE.

7. http://www.antenna-theory.com/basics/main.php 